\section{Presence of Enteramine in the Skin of Amphibia}

THE presence of enteramine has already been demonstrated (by means of colour reactions, pharmacological reactions and, quite recently, by the method of chromatography on paper ${ }^{1}$ ) in acetoneand alcohol-extracts of posterior salivary glands of Octopus vulgaris and Eledone moschata, ${ }^{2,3}$, of the hypobranchial body of Murex trunculus and Murex brandaris ${ }^{4}$, of the intestine of Ciona intestinalis and Tethium plicatum ${ }^{5}$, as well as of mammalian intestinal mucosa and spleen ${ }^{6,7}$. We now find that the skin of Amphibia should be included in the list of organs and tissues containing enteramine.

So far, acetone extracts of the skin of Bufo bufo bufo, Discoglossus pictus, Rana esculenta, Hyla arborea, Salamandra maculosa and Triton cristatus have been examined. The parathyroid glands of Bufo were extracted separately from the remaining skin. After cleaning with petroleum ether and suitable concentration (in order that $1 \mathrm{ml}$. liquid should correspond to 1-10 gm. fresh tissue), extracts were chromatographed on Whatman No. 1 paper, using the following solvents: $n$-butanol saturated with $N$ hydrochloric acid, $n$-butanol saturated with $3-5$ per cent ammonium hydroxide, butanol-acetic acid-water mixture, amyl alcohol - pyridine - water mixture (2:2:1). $n$-Butanol saturated with $N$ hydrochloric acid was employed as first solvent in bi-dimensional chromatography, followed by the amyl alcoholpyridine-water mixture.

Numerous uni- and bi.dimensional control chromatograms were run with extracts of posterior salivary glands of Octopus vulgaris and Eledone moschata, and also with alcoholic solutions of pure bufotenine, bufotenidine and bufothionine. Numerous 'mixed' chromatograms were likewise obtained by simultaneously applying, on the same point of the paper, two or more skin extracts of different Amphibia, with or without addition of salivary extract of Octopus vulgaris and of pure indolalkylamines.

On the chromatograms of the skin extracts of four out of six Amphibia investigated (negative or doubtful results were obtained from Triton cristatus and Bufo bufo bufo) it was possible to demonstrate a spot due to enteramine (spot $E$ ). Indeed, spot $E$ shows all the characteristic colour reactions given by the enteramine spots obtained with salivary extracts of Octopus vulgaris and Eledone moschata ${ }^{1}$ and cannot be distinguished from these comparison spots. Further, $R_{F}$ values of spot $E$ agree satisfactorily with $R_{F}$ values of the enteramine spots obtained with salivary extracts, with all the solvents tested $^{1}$.

On 'mixed' chromatograms, uni- and bidimensional, of skin extracts of Amphibia and salivary extracts of Octopoda, the enteramine spot is always unique, and its intensity and extension is equal to the sum of the enteramine spots which should develop if the two extracts were chromatographed separately.

Spots given by bufotenine, bufotenidine, bufothionine and dehydrobufotenine show $R_{F}$ values clearly different from those of spot $E$ and of enteramine comparison spots, particularly when using as solvent $n$-butanol saturated with $3-5$ per cent ammonium hydroxide ${ }^{8}$.

The eluates of spot $E$ possess all the peculiar pharmacological actions of enteramine : they stimulate the isolated ostrous uterus of rats and mice, the urinary bladder of dogs, whether isolated or in situ, and they inhibit diuresis in hydrated rats. From a qualitative point of view, no difference exists between the pharmacological reactions induced by eluates of spots $E$ and those induced by eluates of control enteramine spots. From a quantitative point of view, the pharmacological response is in all cases identical for $E$ eluates and enteramine eluates giving in vitro a coupling reaction of the same intensity with the diazonium salt of $p$-nitroaniline (acid medium).

The enteramine contents in equal weights of amphibian skin give the following per cent figures, when referred to a standard salivary extract of Octopus vulgaris (summer 1950 extract, prepared from $14 \cdot 3 \mathrm{kgm}$. fresh tissue) : Discoglossus pictus, 95-110 per cent, Hyla arborea, 45-55 per cent, Rana esculenta, 3-5 per cent, Salamandra maculosa, 3 per cent.

The presence of enteramine in the skin of Amphibia is interesting for many reasons. First, it allows us to include in the enteramine cell system (enterochromaffine system intended in a broad sense) also a part of the chromaffine and argentaffine cells of the amphibian skin, already studied histochemically by one of us (Vialli $\left.{ }^{10}\right)$; secondly, because this fact fits in with many established data we are collecting in order to explain the biological significance of enteramine.

The coupling reaction with diazonium salts and the other colour reactions studied in previous investigations ${ }^{1}$ develop, on chromatograms of amphibian skin, not only the enteramine spot, but also a number of other spots differing for each extract. We shall consider them further in future work which we intend to carry out on a much wider comparative basis than we have done so far. We shall also examine the chemical and pharmacological relations existing between enteramine and other active constituents, particularly basic constituents, of the cutaneous secretion of Amphibia.

Institute of Pharmacology,

V. Erspamer University of Bari.

Institute of Comparative Anatomy,

M. VIALLI University of Pavia. Feb. 20.

1 Frspamer, V., and Boretti, G., Exper., 6, 348 (1950); Arch. int. Pharmacodyn. (in the press).

${ }^{2}$ Vialli, M., and Erspamer, V., Arch. di Fisiol., 40, 239 (1940).

"Erspamer, V., Acta pharmacol., 4, 213 (1948).

- Erspamer, V., Arch. int. Pharmacodyn., 74, 113 (1947); ibid., 76, 308 (1948).

${ }^{5}$ Erspamer, V., Exper., 2, 369 (1946).

'Vialli, M., and Erspamer, V., Arch. Sci. Biol., 28, 101, 122 (1942).

${ }^{2}$ Erspamer, V., Arch. exper. Path. u. Pharmak., 196, 343, 366 (1940).

${ }^{8}$ Vialli, M., and Erspamer, V. (to be published).

- Erspamer, V., and Ottolenghi, A., Exper., 6, 428 (1950).

${ }^{10}$ Vialli, M., Boll. Soc. Ital. Biol. Sper., 8, 1740 (1933); 8, 600 (1934); Arch. Ital. Anat., 47, 376 (1942).

\section{Aldolase Activity in Zinc-deficient Plants}

DisTURBances in the metabolism of phosphate and of carbohydrate in zinc-deficient tomato plants led Reed" to suggest the occurrence of "some block in the enzyme system which controlled a fundamentally important process in the utilization of sugars". 